\title{
Making Business of a Revolutionary New Technology: The Eckert-Mauchly Company, 1945-1951
}

\author{
Lars Heide \\ Copenhagen Business School, Porcelænshaven 18B \\ 2000 Frederiksberg, Denmark \\ heideacbs.dk
}

\begin{abstract}
The paper analyzes John Presper Eckert and John William Mauchly's endeavours to design, sell, and build the revolutionary new technology of the first large, commercial computers. It discusses how Eckert and Mauchly's conceptualization of the computer grew out of their ENIAC and EDVAC projects at University of Pennsylvania. They incorporated their own business to gain profit from production and attain the freedom needed to develop their revolutionary new computer technology through a series of small, separate computer projects with private and government customers. It approaches innovation as a chaotic process and uses uncertainty to conceptualize the basic relations between actors and organizations.
\end{abstract}

Keywords: Eckert-Mauchly Company, EDVAC, ENIAC, John Presper Eckert, John William Mauchly, UNIVAC, University of Pennsylvania.

\section{Introduction ${ }^{1}$}

“... did you ever think it was going to turn out like this? ... my colleague Mr. Eckert and I, independently I think, have developed about the same answer: that, yes, we felt it was going to turn out to be a big thing. It was just to our disappointment that it took so long. But then it always takes a long time to change people's minds, and it takes even longer for us to change an institution." 2

This was how John W. Mauchly, in 1973, recalled the development of the first UNIVAC computer, completed in 1951. He acknowledged that he and John Presper

${ }^{1}$ The paper is based upon extensive material in the archives of Hagley Museum and Library, Wilmington, Delaware, USA (Sperry Corporation Records (acc. 1825), Sperry-Rand Corporation Administrative Records (acc. 1910)) and at the Charles Babbage Institute at University of Minnesota, Minneapolis, Minnesota, USA (Margaret R. Fox Papers (CBI 45), C. E. Berkeley Papers (CBI 50), Mauchly talk 1973 (OH 44)) and extensive literature. Research for this paper was accomplished based upon a grant from Hagley Museum and Library, Wilmington, Delaware, and an Arthur L. Norberg Travel Grant from the Charles Babbage Institute at University of Minnesota.

2 John Mauchly, talk to UNIVAC meeting in Rome in 1973, p.1, interview OH 44, Charles Babbage Institute. 
Eckert did not know where the development would end, when it started in the mid1940s. In contrasts, the histories of the computer industry subscribed to a linear narrative from the ENIAC project during World War II to the IBM System/360 mainframe computer closure in the mid-1960s, and to personal computers and beyond. They discuss either engineering (hardware and software) or business aspects of the development and they, therefore, miss the shaping interaction between markets and engineering, and the crucial role of government in both funding projects and acquiring computers.

An integrated analysis of business, technology, private market, and government market is essential in order to understand how mainframe computers emerged. Further, the linear narrative ignores the size of the endeavor that Eckert and Mauchly faced in the mid-1940s of designing and building a revolutionary new technology, and it ignores the complexity of subsequent development, until IBM established the mainframe computer closure by introducing its System 360 in 1964. The development of revolutionary new technology and establishing its production was never a simple rational simple process. In the mid-1940s, designing and producing mainframe computers required revolutionary new design and basic elements, like adders, memory, storage, and input and output media.

The paper analyzes Eckert and Mauchly's endeavours between 1945 and 1951 to design, build, and sell the revolutionary new technology of the first large, commercial computers in interaction with private and government customers. It approaches innovation as being chaotic and uses uncertainty to conceptualize the basic relations between actors and organizations.

\section{ENIAC and EDVAC: Technical Feasibility and Design of an Operational Computer}

In late 1945, John William Mauchly and John Presper Eckert started exploring what a computer should be and its commercial potential. This was based upon the ENIAC project, which had proved the feasibility of building a large electronic computer, and the EDVAC project, which had produced a feasible rapid-access memory, the stored program design and opened for more complex use than calculating the third root of 2,589 raised to the sixteenth power.

In August 1942, John Mauchly wrote a memorandum on a large high-speed vacuum-tube calculator for the Army Ordnance Department. The proposal outlined the main features of a digital vacuum-tube calculator and focused on its technical feasibility. This became the basis for a contract on a large electronic computer, which the Army awarded to the Moore School. Eckert and Mauchly's project team designed new electronic circuits and built a reasonably reliable machine. By June 1944, the formal design of the computer was completed and it was dedicated in February 1946 as the Electronic Numerical Integrator and Computer (ENIAC).

ENIAC proved the feasibility of building a large electronic computer, but it did not have reliability, size, moderate energy consumption, and user friendliness needed in order to make it attractive for a wider range of public and private organizations.

Based on discussions between Moore School and Army Ballistics Research Laboratory, in October 1944, the Army granted a supplement to the ENlAC contract 
to develop a computer, EDVAC, which was easier to use for calculations. During 1945 , this project ran in parallel with the completion of ENIAC, which had priority.

\section{Shaping a Computer}

In the summer of 1945 , the building of large computers became technically feasible. ENIAC was being completed and had proven the feasibility of large electronic computers.

In December 1945 - while completing the ENIAC - Eckert and Mauchly started envisioning commercial possibilities. They approached the Bureau of the Census in order to sell the idea of a large-scale electronic digital computer as an efficient tool for census work. For this end Mauchly and Eckert studied census data processing, and probably magnetic tape was a significant sales argument. In the summer of 1945, the EDVAC design applied magnetic tape or wire for input and output.

However, it was not simple to accommodate commercial production at a non-profit university, such as University of Pennsylvania. In the spring of 1946, Eckert and Mauchly resigned from Moore School because they wanted to exploit the commercial opportunities of building computers.

The ENIAC and EDVAC projects had been classified because of World War II. The end of hostilities facilitated declassification, which enabled Eckert and Mauchly to use their expertise for business. In addition, war-funding disappeared and public funding would again have to be based upon Congressional appropriations. The new funding structure was probably a major reason that Eckert and Mauchly since December 1945 worked to attain a contract to build a computer for the Bureau of the Census. By the spring of 1946, the Census Bureau was definitely interested in Mauchly's proposal.

At their resignation from University of Pennsylvania in March 1946, the possible census contact was the only contract, which they found was at hand. They started to work for establishing a company to develop a multi-purpose rapid computing machine. Though they only were negotiating a contract with the Bureau of the Census, they optimistically envisioned many business opportunities in scientific computations, bookkeeping, and record management. They cited scientific calculations at universities, government agencies, and industries, bookkeeping in large companies, particularly insurance and railroad, and record management in insurance companies and libraries. This was a revolutionary new way to see computers compared to ENIAC and EDVAC.

However, the end of World War II caused a fundamental change in public funding of projects. During the war, funds were amble for war-related projects like ENIAC and the EDVAC pre-project and the trust needed for funding was accomplished quite informally, when the project was located at a well-estimated institution like the Moore School. Now, peacetime appropriation made it essential for a public organization to establish the trust needed to award a project to an organization. Was the project feasible? Was the price reasonable? Did the organization have the technological and financial capabilities needed to complete the contract in due time? It was not simple answering these questions for funding a project with Eckert and Mauchly of building a computer for the Census Bureau. They had substantial technological expertise; 
however, did it suffice to build a revolutionary new device? Moreover, Eckert and Mauchly's business was not yet incorporated and had little assets. It was essential to find a way to establish the needed trust, which required assessment by experts, public or private, acting as intermediaries between the Census Bureau and Eckert and Mauchly. The National Bureau of Standards rose to become the intermediary for civilian and military government computer projects.

By June of 1946, the National Bureau of Standards had decided to award a study contract to Eckert and Mauchly. The two inventors then formed a partnership, but the study contract only became effective in October 1946. Originally, they anticipated that the research and study phase would last six months. They expected to complete the design phase within the next six months. This schedule proved to be overly optimistic. The research and study phase itself lasted a full year. Moreover, it was not until June 1948, that they signed the actual design contract.

The Census Bureau was prepared to spend $\$ 300,000$ on the Eckert-Mauchly computer, of which $\$ 55,400$ went to the National Bureau of Standards for services as the intermediary. In June 1946, Eckert and Mauchly's had estimated the development cost at $\$ 400,000$. Anyhow, despite their limited assets, the two men were willing to absorb the anticipated loss, because they believed that if they were successful, additional machines could be sold to both government and industry at substantial profits.

The Census Bureau needed a different computer than the sophisticated calculator, which was the objective of building ENIAC and EDVAC. Census processing required facilities for producing double entry tables and it took advantage of the plan to use magnetic tape in the EDVAC project. It needed fast and reliable sorting, which Eckert and Mauchly suggested could be achieved through transmission of data between two magnet tapes operating at separate stations. This made construction of tape stations and fast exchange of data between tape and the computer a key element of the Census Bureau contract. The computer was changing from a fast calculator into a smart punched card machine. This transformation was more complicated and time consuming than Eckert and Mauchly anticipated.

The situation of late assignment of government contracts, which were smaller than expected, and more work in designing and building the computer than anticipated made Eckert and Mauchly open for approaches for additional contracts from A. C. Nielsen Company, and Prudential Insurance Company.

The A. C. Nielsen Company was founded in 1923 in Chicago, Illinois, by Arthur C. Nielsen, Sr., in order to give marketers reliable statistics on impact of marketing and sales programs. In the mid-1940s, A. C. Nielsen Company used large punched card installations to process the data for their market statistics. Nielsen was interested in investing in new development, even in a small company, despite the obvious risk and started negotiations with Eckert and Mauchly in December 1946.

In January 1947, Eckert and Mauchly offered to sell A. C. Nielsen Company a computer system equipped with a key-to-tape recorder and a printer, all units to be completed within a year. This implied changing the basis for Nielsen's data processing from punched cards to magnetic tape, which they accepted. But A. C. Nielsen Company was reluctant to sign a purchase agreement with Eckert and Mauchly's company because of its precarious financial position. Nielsen wanted Eckert and Mauchly to develop their equipment and gain more business in order to establish the trust, which it needed for awarding a contract for a computer system. 
Over the next year, Eckert and Mauchly reshaped their computer system and particularly its peripherals based upon their discussions with Prudential Insurance Company. The A. C. Nielsen Company only needed a computer similar to that already promised to the Bureau of the Census. In April 1948, Nielsen signed a contract for a computer system with several peripherals. The system included one computer, six tape units, six key-to-tape units, and one printer.

Simultaneously with the negotiations with A. C. Nielsen Company, Eckert and Mauchly negotiated with Prudential Insurance Company of Newark, New Jersey. The negotiations with Prudential made Eckert and Mauchly extend the scope of their computer project to encompass alphanumeric data processing, because the Eckert Mauchly Company realized that Prudential demanded equipment for premium billing, mortality studies, and group insurance. Premium billing presupposed letters and numbers.

Prudential's data processing was based on IBM equipment since the 1920s. Therefore, it viewed the Eckert and Mauchly's use of magnetic tape for input and output with concern. Although the concept seemed attractive, there yet was no working model to prove its feasibility, and the use of tapes in place of cards would mean that Prudential's entire data processing operation would need conversion to tape. Eckert and Mauchly convinced Prudential that their computer system was feasible and a superior alternative to its current IBM punch-card systems, which caused two concerns at Prudential. Eckert and Mauchly's uncertain financial position was a serious obstacle. Prudential was unwilling to sign a large contract with a small company that had serious financial problems, particularly when sizable investment was required to complete the contract. This was the case, because Eckert and Mauchly had not yet accomplished designing the statistics computer for the contracts with the Bureau of the Census and A. C. Nielsen Company, and Prudential's alphanumeric requirements would imply additional research and development as well as production expenses.

While Prudential was not willing to contract for a machine, it signed an agreement with Eckert and Mauchly, in August 1947, where it funded development of the computer system in return for an option to buy one later. If the option was exercised, the money provided for development would be applied to the purchase. The agreement promised to complete the design and several prototypes of several key elements of the computer system by the end of 1947. Once more Eckert and Mauchly were overly optimistic in their time estimate. By the end of 1947, they had no yet completed the prototype, and Prudential could have insisted that half its funds be returned. Instead, it agreed to amend the contract several times to allow Eckert and Mauchly's company more time to fulfill its obligations. Prudential extended the deadlines because it was impressed with the progress being made and the development contract made it dependent on Eckert and Mauchly. In the end, Prudential signed a contract in December 1948 for building a computer system. The contract called for one card-to-tape converter and two tape-to-card converters, devices that would allow Prudential to retain its punch-card data processing systems. This was essential for Eckert and Mauchly extending their market to encompass non-numeric data processing, for example, in insurance companies. The Prudential contract described Eckert and Mauchly's complete computer system, which they had named UNIVAC a year earlier, Universal Automatic Computer. It had a central computer, 
tape drives, alphanumeric key-to-tape encoders, and line printers. In order to answer demand, Eckert and Mauchly had developed their original ENIAC and EDVAC number cruncher design into an alphanumeric design for data processing to succeed extensive punched card business.

\section{Establishing Business of Computers}

Eckert and Mauchly left the Moore School of University of Pennsylvania in March 1946, because they saw bright possibilities of computer business and they founded a partnership as the basis for their work. They focused on developing a computer and attaining computer-building contracts through 1946 and 1947, and Mauchly travelled extensively to win over customers. In this period, they established contacts with A. C. Nielsen Company and Prudential Insurance Company, which contracted for computers in 1948. In addition, the records show that Mauchly had contacts to about twenty additional private and public organizations prospects in 1946-1947, which did not produce contracts.

Eckert and Mauchly only incorporated their business in December 1947 and it was named Eckert-Mauchly Computer Corporation. Though the company attained several substantial contracts in 1948, its financial problems became more severe during that year. Since the start of the year, Mauchly worked hard to attack additional customers based upon a strategy to produce the company out of its crisis. The company was desperate to securing adequate capital to assure the government and private companies that they could complete contracts that they would make, and the company failed to raise substantial new capital by issuing additional stocks in April 1948.

However, in the summer of 1948, new capital came from American Totalistor Company of Baltimore. John Straus, its vice president, saw possibilities of computers applied as totalisators. He convinced his company to invest $\$ 500,000$ in in return for 40 percent of the voting common stock of Eckert-Mauchly Computer Corporation. American Totalisator's support kept Eckert and Mauchly's company floating for fourteen months, during which development on UNIVAC continued. In October 1949, Eckert and Mauchly's company received an additional $\$ 100,000$ from American Totalisator. Anyway, the company's problems were not yet solved. Nine days later, Henry Straus was killed when his small airplane crashed. Straus had been the prime force behind Totalisator's support and his death terminated the flow of funds from this company.

As a direct result of Straus's death, Eckert and Mauchly spent the remaining months of 1949 seeking financing from loan companies and research foundations. Finally, they sought to sell their corporation to a major manufacturer. They approached producers of calculating equipment, such as Burroughs, IBM, National Cash Register, and Remington Rand. Subsequently, they approached major industrial producers, such as General Motors.

Remington Rand was first to act, and on 1 February 1950, it purchased all the shares of the Eckert-Mauchly Computer Corporation. It became a subsidiary of Remington Rand and functioned as a separate division. It delivered the first UNIVAC computer to the Bureau of the Census in March 1931. By October 1954, Remington Rand had delivered twelve UNIVACs and had orders for four more. 


\section{Mess of Making Business of a Revolutionary New Technology}

I started the paper by citing John W. Mauchly's reminiscence, in 1973, of the shaping of what became the UNIVAC computer. He admitted that the shaping process was protracted, which he explained by observing, "...it always takes a long time to change people's minds, and it takes even longer for us to change an institution."

He was correct that institutions - which he conceptualized as private and public organizations - had to change, but this only occurred once computers were installed. In the late 1940s, the organizational change of customer to demand computers had short duration compared to the at least five years, which Eckert and Mauchly spent in designing and building the first large computer. In contrast, Mauchly persuaded the Census Bureau in five months to order a computer system, A. C. Nielsen Company used between two and three months to reach a decision, and Prudential Insurance Company reached their decision in less than a year. However, it took much more time to establish the trust needed for these organizations to sign contracts. They were uncertain of Eckert and Mauchly's company's financial capability, and they did not want to be dependent on technology which perhaps never would materialize.

The demand for reduction of uncertainty and dependency gave room for the National Bureau of Standards to establish itself as the national computer intermediary facilitating civilian and military contracts.

Further, Mauchly underestimated the extent of developing a revolutionary new technology twenty-five years after it took place, as he and Eckert did while they explored the new technology between 1943 and 1951. Before starting computer production, they had to establish company standards for designing and building completely new technology, based upon many components with reliability problems. Through this process, the scope of their computer's planned applications grew from the original number cruncher (ENIAC and EDVAC), to the numerical statistics calculator for the Census Bureau and A. C. Nielsen Company, and to the alphanumeric data processing machine for Prudential Insurance, which was named UNIVAC. Each extension of applications added a new element of uncertainty to the project. However, Eckert and Mauchly rejected an enquiry in 1946 of developing their computer for totalisator applications, which illustrates that they did not pick all requests. Their choices of customers remained within the scope they envisioned in the spring of 1946 and gradually expanded their business opportunities.

At each expansion, Eckert and Mauchly accepted new uncertainty, because they depend on one more customer to fill their company's extensive need for funds to complete their previous assignment. Their perpetual search for new customers, made Mauchly commit extensive time to locate and persuade new customers. Often, Eckert, who should have committed all his time to complete their technical project, accompanied him. The records of Eckert and Mauchly's company provide a hectic picture of searches for funding that took time and delayed the project. Already in the summer of 1947, they had also to borrow money from Prudential Insurance to be able to keep their computer development project floating. In 1948, they received substantial capital from American Totalisator. However, only access to the large financial resources of the Remington Rand conglomerate, in 1950, facilitated completion and production of UNIVAC computers. 
Eckert and Mauchly's first large computer and their business were shaped through dependency on a series of customers for expertise on future use of computers and funds for innovating computers. At first glance, the technical development process and the search for additional customers may seem chaotic, and, certainly, they held many chaotic elements. However, Mauchly was correct in 1973 to claim that he and Eckert all the way went for a general objective, which they accomplished though in Remington Rand, a different business context than they originally anticipated. 